\title{
Meningoencefalitis por influenza A pH1N1. Presentación de un caso clínico
}

\author{
Influenza A pH1N1 meningoencephalitis. A case report
}

\author{
Dr. Pablo Melonari ${ }^{a}$ Dra. Carolina Rodríguez Saáa y Dr. Héctor Abate ${ }^{a}$
}

\section{RESUMEN}

El virus influenza produce epidemias y pandemias con alta morbilidad-mortalidad. Según datos de la Organización Mundial de la Salud, causa 3-5 millones de casos de enfermedad grave y 250000 a 500000 muertes cada año. La enfermedad es fundamentalmente respiratoria y las complicaciones más frecuentes son: neumonía, descompensación de enfermedades subyacentes $\mathrm{y}$, menos frecuentemente, complicaciones no respiratorias. Se presenta un paciente de 6 años con meningoencefalitis por la nueva cepa influenza A (IA) pH1N1, con documentación viral en líquido cefalorraquídeo (LCR). Se detallan hallazgos clínicos, de laboratorio e imágenes del caso, el cual evolucionó favorablemente con secuelas. Resulta de gran importancia clínica y epidemiológica el conocimiento de esta forma de presentación, debido a la escasa evidencia científica publicada internacionalmente.

Palabras clave: subtipo H1N1 del virus de la influenza A, meningoencefalitis, manifestaciones neurológicas.

\section{SUMMARY}

The influenza virus causes epidemics and pandemics with high morbidity and mortality. According to the World Health Organization, this virus causes 3-5 million cases of severe illness and 250,000 to 500,000 deaths each year. The disease is mainly respiratory and the most common complications are pneumonia, exacerbation of underlying diseases and less frequently respiratory complications. We report a 6-year-old patient with meningoencephalitis due to a new influenza A (IA), strain $\mathrm{pH} 1 \mathrm{~N} 1$, with viral documentation in cerebrospinal fluid (CSF). We provide detailed clinical, laboratory and imaging of the case, which responded favorably to sequels. Knowledge of this form of presentation is of great clinical and epidemiological significance due to the limited scientific evidence published internationally.

Key words: virus, H1N1 subtype of influenza A, meningitis, neurological manifestations.

http:/ /dx.doi.org/10.5546/aap.2013.e10

a. Servicio de Infectología, Hospital Pediátrico "Humberto Notti". Mendoza. Argentina.

Correspondencia:

Dr. Pablo Melonari: pa_melonari@yahoo.com.ar

Conflicto de intereses: Ninguno que declarar.

Recibido: 12-4-2012

Aceptado: 25-7-2012

\section{INTRODUCCIÓN}

El virus de la gripe afecta a individuos de todas las edades. A partir del alerta de la Organización Mundial de la Salud (OMS) en abril de 2009, se registró la primera pandemia de gripe de este siglo, debido a una nueva cepa de Influenza A (IA) pH1N1 (A/California/7/2009). El virus se extendió rápidamente por todos los países del mundo, con epidemiología similar. Ese año, en la Argentina se registraron cerca de 10000 casos confirmados y más de 500 defunciones. En la mayoría de los niños la enfermedad es autolimitada, pero en los más pequeños y con enfermedad subyacente puede ser grave. Habitualmente se presenta como un cuadro respiratorio agudo, de intensidad variable, dependiendo de las características del virus, de la edad del sujeto y el estado de salud. Las complicaciones en el sistema nervioso central (SNC) son muy poco frecuentes, de allí la importancia de presentar este caso clínico, como una modalidad de encefalitis aguda por acción directa del virus IA pH1N1.

\section{CASO CLÍNICO}

Paciente de 6 años, sexo masculino, que consultó en forma ambulatoria por fiebre $\left(38^{\circ} \mathrm{C}\right)$ más odinofagia de 5 días. Se diagnosticó amigdalitis y recibió penicilina V 750000 U cada 12 h, vía oral, 4 días. Presentó vómitos y una deposición diarreica sin moco ni sangre. Continuó febril $\left(38,6^{\circ} \mathrm{C}\right)$ y luego presentó cefaleas, somnolencia, desorientación temporoespacial, trastornos de la marcha y respuesta verbal disminuida. Consultó el 02/07/2011 en Emergencias del Hospital Notti y se internó.

Esquema de vacunación de calendario nacional incompleto, no recibió vacuna antigripal ni antiinflamatorios no esteroideos (AINE). Peso: $35,800 \mathrm{~kg}$, talla: $120 \mathrm{~cm}$ e IMC: 24,86 mayor al percentilo 95 para la edad.

Sin antecedentes patológicos o familiares de relevancia.

Examen físico: regular estado general, afebril, frecuencia cardíaca: 120 latidos/min, frecuencia respiratoria: 30 respiraciones/min, tensión arterial: 120/100 mmHg. Hemodinámicamente com- 
pensado. Examen neurológico: Glasgow 12/15, desorientado, irritable, obedecía a órdenes simples, disartria, disbasia, disminución de la fuerza en miembros inferiores, reflejos osteotendinosos aumentados, sin signos meníngeos ni de foco. Resto del examen normal.

Se realizó estudio de LCR, hemocultivos y cultivo de fauces. Se inició tratamiento empírico con ceftriaxona a $100 \mathrm{mg} / \mathrm{kg} /$ día c/ $12 \mathrm{~h}$ y acyclovir a $30 \mathrm{mg} / \mathrm{kg} /$ día c/ $8 \mathrm{~h}$, intravenosos (IV).

Presentó desmejoría clínica a las $24 \mathrm{~h}$ del ingreso. Se constató pérdida de control de esfínteres anal y urinario, signos de Kerning, Brudzinsky y Babinsky positivos, hemiparesia facio-braquiocrural derecha e hipertonía contralateral.

Tomografía axial computada (TAC) de cerebro: normal. Resonancia magnética nuclear (RMN) de cerebro y columna (Figura 1): áreas hiperintensas en núcleos lenticulares con predominio en putamen izquierdo a nivel cortical ipsolateral y en sustancia blanca subcortical de ambos hemisferios cerebrales; ligera hiperintensidad bicordonal simétrica en médula espinal dorsal. Hallazgos compatibles con encefalomielitis diseminada aguda (EMDA). Laboratorio: leucocitos $10100 \mathrm{cel} / \mathrm{mm}^{3}$, neutrófilos en cayado: $0 \%$, neutrófilos segmentados: $75 \%$, eosinófilos: $3 \%$, basófilos: $0 \%$, linfocitos: $17 \%$, monocitos: $5 \%$, hematócrito $36 \%$, plaquetas $337000 / \mathrm{mm}^{3}$, proteína C-reactiva $0,9 \mathrm{~g} / \mathrm{L}$, función hepática y re-

FIgURA 1. RMN de cerebro: áreas hiperintensas en núcleos lenticulares y signos de desmielinización en ambos hemisferios cerebrales

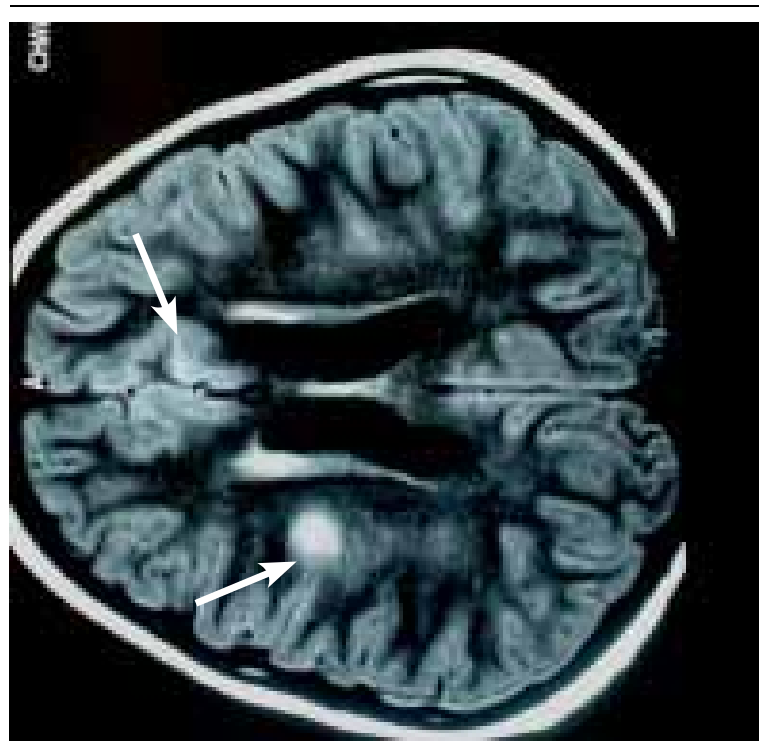

nal normal. LCR incoloro, límpido, recuento de leucocitos: $30 \mathrm{cel} / \mathrm{mm}^{3}: 60 \%$ polimorfonucleares - 40\% linfocitos; proteinorraquia $0,27 \mathrm{~g} / \mathrm{L}$; glucorraquia $0,55 \mathrm{mg} / \mathrm{dl}$ (glucemia: $82 \mathrm{mg} / \mathrm{dl}$ ); reacción de Pandy negativa; xantocromía negativa. Electroencefalograma (EEG): ondas lentas, a predominio posterior. Rx tórax normal. Fondo de ojo: normal. Ecocardiograma: normal. Serología en sangre para Mycoplasma pneumoniae (ELISA) IgG e IgM positivas, Inmunofluorescencia para adenovirus, influenza A y B, parainfluenza 1, 2 y 3 y virus respiratorio sincicial (VRS) en aspirado nasofaríngeo (ANF) no realizados. Hemocultivos, cultivo de fauces y de LCR para bacterias negativos. Reacción en cadena de la polimerasa (PCR) en LCR para herpes simplex de tipos 1 y 2 , citomegalovirus (CMV), adenovirus y enterovirus negativos. Reacción en cadena de la polimerasa, tiempo real (PCR-RT), para IA pH1N1, positivo en LCR.

Se indicó metilprednisolona a $30 \mathrm{mg} / \mathrm{kg} /$ día, al $4^{\circ}$ día de internación, por desmejoría neurológica y ante la sospecha de enfermedad desmielinizante aguda postinfecciosa. Se suspendió acyclovir, por PCR negativa para herpes, y ceftriaxona, por cultivos negativos. Ante el cuadro respiratorio y serología positiva para $M$. pneumoniae se indicó claritromicina a $15 \mathrm{mg} / \mathrm{kg} /$ día, IV, por 14 días. Recibió oseltamivir a $60 \mathrm{mg}$, vía oral, cada 12 h, 5 días.

Presentó mejoría clínica con el tratamiento y recuperó la deambulación, el estado de conciencia y el control de esfínteres; al alta hospitalaria persistió con disminución de la fuerza muscular generalizada, hemiparesia, estrabismo de ojo derecho, disartria y lentitud en la respuesta verbal.

\section{DISCUSIÓN}

Las complicaciones neurológicas de la gripe han sido descriptas desde 1918, tales como encefalitis letárgica, EMDA, síndrome de Guillain-Barré, mielitis transversa y la encefalopatía necrosante aguda (ENA). ${ }^{1}$

En la Argentina, la pandemia de IA pH1N1 de 2009 provocó cerca de 10000 casos confirmados, con alto impacto en pediatría. ${ }^{2}$ La morbimortalidad fue elevada.

En un estudio multicéntrico de la Argentina en niños de 0-18 años, la forma clínica de presentación más frecuente fue la neumonía y sólo 10 niños presentaron convulsiones $(1,35 \%)$ concomitantemente a la infección viral. En los 741 sujetos positivos, no se documentó la presencia del virus, con RT-PCR en el SNC. ${ }^{3}$ 
En los EE.UU., en mayo de 2009, en una serie de cuatro casos pediátricos, se informó por primera vez encefalopatía asociada con IA pH1N1. Los niños del informe del CDC tenían 7, 10, 11 y 17 años. Los cuatro presentaron signosintomatología neurológica. Algunos experimentaron adormecimiento, debilidad, desorientación y lentitud en la respuesta verbal. Dos tuvieron convulsiones. Tres presentaron EEG anormales. En los 4 pacientes se detectó ARN viral de IA pH1N1 en ANF, pero no en LCR. ${ }^{4}$

En Japón, aproximadamente el 18\% de ENA se han asociado con infección por IA; la cepa más frecuente fue H3N2. ${ }^{5}$ En Italia, una niña de 3 años con ENA, manifestó compromiso neurológico grave, rápidamente progresivo. Se afectaron ganglios de la base, tronco cerebral y sustancia blanca. Antecedentes: ingestión de AINE y disfunción hepática grave concomitante, situación que no se registró en nuestro paciente. Se detectó virus en ANF, pero no en LCR. ${ }^{6}$

Durante la pandemia de 2009, las anomalías en las neuroimágenes de ENA, fueron observadas por primera vez en un niño de Texas. ${ }^{7}$ Posteriormente, dos casos más por Haktanir en Turquía. ${ }^{8}$ En nuestro caso, la RMN mostró lesiones desmielinizantes compatibles con EMDA, entidad que se ha descripto como secundaria a diferentes infecciones, entre ellas la IA. Las alteraciones aparecen alrededor de 14 días postinfección (intervalo: 8-21 días). ${ }^{9}$

Fue confirmado un caso de encefalopatía que progresó a muerte cerebral con infección confirmada (no en LCR). ${ }^{10}$

Una encuesta de 94 hospitales japoneses durante 8 temporadas de gripe, previo a la pandemia 2009, informó que sólo el $10 \%$ de los casos presentaba IA no pH1N1, por RT-PCR en LCR. ${ }^{11}$

En la India, se describió un caso de encefalitis aguda en un niño de 9 años, con algunas similitudes con nuestro caso clínico, pero con detección en ANF. ${ }^{12}$

Se desconoce si el virus ingresa físicamente en el SNC o si la disfunción neurológica es secundaria. En exámenes postmortem se evidencian hemorragias petequiales, congestión de vasos intraparenquimatosos talámicos, microtrombos y edema vasogénico, lo cual sugiere que la disfunción del SNC puede deberse a daño vascular, sin penetración directa del virus a través de la barrera hematoencefálica. ${ }^{5}$

Existen varias hipótesis en relación con la patogenia del compromiso neurológico del virus. Las concentraciones plasmáticas elevadas de in- terleucina 6 y factor de necrosis tumoral- $\alpha$, podrían ser mediadores del daño; ${ }^{3}$ pero no todos los informes muestran su elevación ${ }^{13}$ y rara vez evidencian presencia del virus en el SNC, dato que es referido por la mayoría de los autores. ${ }^{14}$ Numerosos trabajos carecen de PCR-RT para IA H1N1 ya que son citas de años previos.

La PCR en tiempo real fue la técnica recomendada por la OMS para el diagnóstico rápido y precoz de los pacientes con sospecha de infección por el nuevo virus. ${ }^{15}$

El paciente demuestra un claro ejemplo de efecto citopático directo del virus IA pH1N1 en SNC, por múltiples razones: presencia de compromiso neurológico grave durante la etapa aguda de la infección, lesiones precoces demostradas en neuroimágenes del SNC, sin otra explicación y la detección del ARN viral en LCR.

Las nuevas líneas de estudio resultan importantes para identificar los mecanismos fisiopatológicos, diagnósticos y terapéuticos que permitan un manejo adecuado de estos pacientes.

Ante la presencia de un cuadro neurológico grave, los pediatras deben sospechar la probable etiología por IA pH1N1, de acuerdo al contexto epidemiológico en el que se detecte el caso.

\section{BIBLIOGRAFÍA}

1. Vilensky JA, Foley P, Gilman S. Children and encephalitis lethargica: a historical review. Pediatr Neurol 2007;37:79-84.

2. Ministerio de Salud, Argentina. Notificación al Sistema Nacional de Vigilancia Laboratorial SNVS-SIVILA: Actualización infecciones respiratorias agudas virales, todo el país hasta SE 29 incluyendo influenza A H1N1. Julio 29, 2009. [Acceso: 25 de julio de 2012]. Disponible en: http: / / msal.gov.ar/htm/site/pdf/Epi-29-07.pdf.

3. Gentile A, Bakir J, Russ C, Falaschi A, et al. Estudio de las enfermedades respiratorias por virus Influenza A H1N1 ( $\mathrm{pH} 1 \mathrm{N1}$ ) en niños internados durante el año de la pandemia. Experiencia de 34 centros en la Argentina. Arch Argent Pediatr 2011;109(3):198-203.

4. Centers for Disease Control and Prevention. Neurologic complications associated with novel influenza A (H1N1) virus infection in children-Dallas, Texas, May 2009. MMWR Morb Mortal Wkly Rep 2009;58:773-8.

5. Sugaya N. Influenza-associated encephalopathy in Japan. Semin Pediatr Infect Dis 2002;13(2):79-84.

6. Ormitti F, Ventura E, Summaa A, Picetti E, Crisi G. Acute necrotizing encephalopathy in a child during the 2009 Influenza $\mathrm{A}(\mathrm{H} 1 \mathrm{~N} 1)$ pandemic: MR imaging in diagnosis and follow-up: AJNR Am J Neurol 2010;31(3):396-400.

7. Lyon JB, Remigio C, Milligan T, Deline C, et al. Acute necrotizing encephalopathy in a child with H1N1 influenza infection. Pediatr Radiol 2010;40(2):200-5.

8. Haktanir A. MR imaging in novel influenza A (H1N1)associated maningoencephalitis. AJNR Am J Neuroradiol 2010;31(3):394-95.

9. Siordia Karma L, De Lara Huerta J, Cárdenas Barragán R, Pacheco Siordia S K. Encefalomielitis diseminada aguda postvaricela. Rev Enfer Infecc Pediatr 2006;19(76):126-130. 
10. Martin A, Reade E. Acute necrotizing encephalopathy progressing to brain death in a pediatric patient with novel Influenza A (H1N1) infection. Clin Infect Dis 2010;50(8):50-2.

11. Togashi T, Matsuzono Y, Narita M, Morishima T. Influenza-associated acute encephalopathy in Japanese children in 1994-2002. Virus Res 2004;103(1-2):75-8.

12. Nir S, Ori A, Sameh T, Riva B. Novel Influenza A (H1N1) and acute encephalitis in a child. IMAJ 2010;12(7):446-7.
13. Shinjoh M, Bamba M, Jozaki K, Takahashi E, et al. Influenza A-associated encephalopathy with bilateral thalamic necrosis in Japan. Clin Infect Dis 2000;31(2):611-3.

14. Toovey S. Influenza-associated central nervous system dysfunction: a literature review. Travel Med Infect Dis 2008;6(3):114-24.

15. Jiang T, Kang X, Deng Y, Zhao H, et al. Development of a real-time RT-PCR assay for a novel influenza A (H1N1) virus. J Virol Methods 2010;163(2):470-3. 